\title{
Validation of the Self Regulation Questionnaire as a Measure of Health in Quality of Life Research
}

\author{
A. Büssing ${ }^{1}$, M. Girke ${ }^{2,3}$, C. Heckmann ${ }^{1}$, F. Schad ${ }^{2,4}$, T. Ostermann ${ }^{1}$, M. Kröz ${ }^{2,3}$ \\ ${ }^{1}$ Chair of Medical Theory and Complementary Medicine, Faculty of Medicine, University Witten/Herdecke, Herdecke, Germany \\ ${ }^{2}$ Havelhöhe Research Institute (FIH), ${ }^{3}$ Department of General Internal Medicine, and ${ }^{4}$ Department of Gastroenterology \\ at the Community Hospital Havelhöhe, Berlin, Germany
}

\begin{abstract}
Objectives: Several epidemiological studies address psychosomatic 'self regulation' as a measure of quality of life aspects. However, although widely used in studies with a focus on complementary cancer treatment, and recognized to be associated with better survival of cancer patients, it is unclear what the 'self regulation' questionnaire exactly measures.

Design and Setting: In a sample of 444 individuals (27\% healthy, $33 \%$ cancer, $40 \%$ other internal diseases), we performed reliability and exploratory factor analyses, and correlated the 16-item instrument with external measures such as the Hospital Anxiety and Depression Scale, the Herdecke Quality of Life questionnaire, and autonomic regulation questionnaire.

Results: The 16-item pool had a very good internal consistency (Cronbach's alpha $=0.948$ ) and satisfying $/$ good $\left(r_{r t}=0.796\right)$ test-retest reliability after 3 months. Exploratory factor analysis indicated 2 subconstructs: (1) Ability to change behaviour in order to reach goals, and (2) Achieve satisfaction and well-being. Both sub-scales correlated well with quality of life aspects, particularly with Initiative Power/Interest, Social Interactions, Mental Balance, and negatively with anxiety and depression.

Conclusions: The Self Regulation Questionnaire (SRQ) was found to be a valid and reliable tool which measures unique psychosomatic abilities. Self regulation deals with competence and autonomy and can be regarded as a problem solving capacity in terms of an active adaptation to stressful situations to restore wellbeing. The tool is an interesting option to be used particularly in complementary medicine research with a focus on behavioural modification.
\end{abstract}

\section{INTRODUCTION}

In the last decade the large application of health-related quality of life (HRQL) questionnaires in medicine brought important new aspects for the treatment of patients with chronic conditions, but disclosed the limitations of generic and disease specific HRQL questionnaires [1]. New studies gave some evidence that questionnaires capturing the individual skills of adaptation, i.e., as sense of coherence or self-regula- tion, could be more appropriate as prognostic tools in oncology or in different chronic conditions than classical HRQL scales [2, 3]. One of these measures is the psychosomatic 'self-regulation' [4-8] which was exclusively used in studies with a focus on complementary cancer treatments. Self-regulation (SR) was reported to represent the "ability actively to achieve well-being, inner equilibrium, appropriate stimulation, a feeling of competence, and a sense of being able to control stressful situations" [4].

However, until now it is unclear what the 16-item SR instrument exactly measures, and thus whether the assessment of SR is in fact a measure of HRQL aspects as suggested by Grossarth-Maticek and Ziegler $[4,9]$, or is a facet of other concepts such as coping, coherence, locus of health control to achieve well-being. To address these questions is of outstanding relevance, because higher SR scores were found to be associated with the unwillingness of cancer patients to participate in double-blind clinical studies [4], but were nevertheless associated with longer survival times when treated with plant extracts from Viscum album L. [5-9] which are widely used in Europe for complementary cancer treatment.

In the presented study we intended to investigate reliability, factorial structure and validity of the SR questionnaire in a group of internal medicine patients and healthy controls to draw valid conclusions about the association between survival, self regulation and usage of complementary medicine.

\section{MATERIALS AND METHOds}

\section{PARTICIPANTS}

In this survey, we analyzed the data of 444 individuals. Patients and healthy control persons were informed of the purpose of the study, assured of confidentiality, gave consent to participate, and completed the questionnaire by themselves. The patients were recruited consecutively in 2000 and 2001 from the Departments of General Internal Medicine, Gastroenterology and Cardiology at the Gemeinschaftskrankenhaus Havelhöhe, the specialist oncology practice at the same hospital, at an oncological practice in Öschelbronn, and 
an endocrinological practice in Wuppertal. Healthy controls were recruited among the hospital staff, their families and among visitors (convenience sample).

Seventy-two \% were women, 28\% men (mean age $57 \pm 14$ years). Twenty-seven $\%$ were healthy, 21\% had breast cancer, 11\% colorectal cancers, 13\% diabetes mellitus (types 1 and 2), 6\% rheumatic diseases, 9\% coronary heart diseases, 7\% Hashimoto's thyreoiditis, and 5\% multiple conditions. 227 participants have been retested $13.1 \pm 7.8$ weeks later.

Among the healthy individuals, $71 \%$ were female and $29 \%$ male (mean age $54.2 \pm 14.3$ years).

Patients were slightly older than healthy controls. With the exception of coronary heart diseases (33\% women, $67 \%$ men), and diabetes (48\% women, $52 \%$ men), women were predominating in the respective disease groups (i.e., breast cancer 100\%; Hashimoto's thyreoiditis $100 \%$; rheumatic diseases $79 \%$; colon carcinoma 61\%).

\section{MeAsures}

SR was measured with a 16-item pool $[4,10]$, and uses 6-point likert scales ranging from 1 (very weak) to 6 (very strong). Scores 5-6 of the primary tool were assumed to indicate very good SR, scores 4-5 good SR, scores 3.5-4 moderate SR, scores 2-3.5 weak SR, and scores 1-2 very poor SR [4, 10]. For the re-validated instrument (SRQ), we decided to use the primary ratings (scores 1-6) and referred them to a $100 \%$ level. Thus, scores $<50$ will represent lower SR, while scores $>50 \%$ indicate higher SR.

To test the external validity of the scale and to make statements about the conceptual relationships between SR and quality of life, we enrolled several other instruments:

\section{Quality of life:}

The HLQ-questionnaire (with five point Likert-scale; Cronbach's alpha $=0.935$ ) differentiates the following factors: Initiative Power \& Interest; Social Interactions; Mental Balance; Motility; Physical Complaints; Digestive Well-Being [11]. For this analysis the HLQ scales Initiative Power \& Interest (i.e. good ideas, decisive, take initiative, spontaneous reactions, adaption to others and situations, put plans into action, etc.), Social Interactions (i.e., feelings of comfort with others, over-directed, left out, abandoning community life, family life a burden, etc.) and Mental Balance (i.e., nervous/irascibly, well-balanced, happy) were of particular relevance.

\section{Anxiety and depression:}

The Hospital Anxiety and Depression Scale (HADS) is a highly reliable and valid 14-item instrument which differentiates anxiety and depression. It is a four point Likert-scale with a range from $0-21$ for both. Higher scoring indicate more symptoms, i.e., $\geq 11$ points anxiety or depression are probable, $\geq 8-10$ possible cases, $<7$ no cases $[12,13]$.

\section{Autonomic functioning:}

The 12-item 'Autonomic regulation' (aR) scale measures the state of regulation of different autonomic functions in the rhythmic change of rest and activity (and thus is not identically with the cognitive concept of 'self-regulation'). The respective subscales of the long version Orthostatic-Circulatory, Rest/Activity and Digestive Regulation had a satisfying internal consistency (Cronbach- $\alpha$ : $r \alpha=0.65-0.75)$, and satisfying $/$ good test-retest reliability $\left(\mathrm{r}_{\mathrm{rt}}=0.70-85\right)$, and good validity $[14,15]$. We used a 12 -item short form (three point Likert-scale) which includes items which pertain to autonomic functions such as rest/activity rhythms, vertigo, orthostatic regulation, and thermoregulation. Additional questions on activity aim to record self-reported sleep duration and quality, as well as day-time functioning which could reflect the rest/activity rhythm.

\section{STATISTICAL ANALYSis}

All data were treated as ordinal data. Cronbach's coefficient alpha [16] was used to evaluate the reliability of our questionnaire and inter-item correlations as published previously [17]. The reliability of the scale was evaluated with internal consistency coefficients. To combine several items with similar content, we relied on the technique of factor analysis (principal component analysis) using Varimax Rotation with Kaiser Normalization. Test-retest reliability has been measured with Spearman Correlation.

Reliability and factor analyses, analyses of variance (ANOVA), and correlation analyses were performed with SPSS 15.0 for Windows (SPSS GmbH Software, Munich). We judged $\mathrm{p}<0.05$ as significant.

\section{RESULTS}

\section{RELIABILITY AND FACTOR ANALYSIS}

Reliability analysis of the 16-item pool (Table 1) revealed that the construct had a very good internal consistency (Cronbach's alpha $=0.95)$. The item difficulty (3.99 [mean value] / 6) was 0.66. Exploratory factor analysis (main components; eigenvalues $>1$ ) pointed to a 2 -factor solution, which explains $63.2 \%$ of variance (Table 1). With respect to side-loadings, item SR8 from scale 2 would fit also to scale $1(0.517)$, and item SR 7 from scale 1 also on scale 2 (0.421); side-loadings $<0.4$ were not addressed.

Factor 1 can be described as "Ability to Change Behaviour in order to reach goals", and factor 2 as "Achieve Satisfaction and Well-Being", which thus has a hedonistic / eudemonistic connotation. The testretest reliability of the sum-scale was $r_{r t}=0.80$, of the factor $1 r_{r t}=0.76$, and of the factor $2 r_{r t}=0.73$.

\section{Self Regulation Scores in Patients and Healthy}

The Ability to Change Behaviour was significantly higher in men than in women (Table 2), while there were no age-depended differences (data not shown). Patients and healthy individuals differed significantly with respect to their Ability to Change Behaviour and Achieve Satisfaction and Well-Being (Table 2). The highest SR scores were found in healthy controls (which are predominantly of female gender) and pa- 
Table 1. Mean values and reliability parameters of SRQ questionnaire.

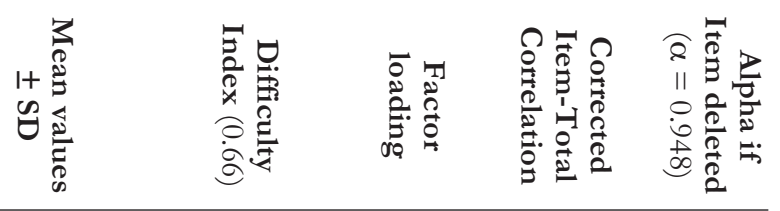

1. Ability to Change Behaviour in Order to Reach Goals ( $\alpha=0.909 ; 31.8 \%$ of variance)

\begin{tabular}{|c|c|c|c|c|c|c|}
\hline SR12 & new behaviour pattern & $3.93 \pm 0.97$ & 0.66 & .790 & .735 & .944 \\
\hline SR11 & change behaviour to reach pleasant outcome & $3.97 \pm 0.98$ & 0.66 & .763 & .752 & .944 \\
\hline SR6 & threatening situations: behave to emerge safe & $4.27 \pm 1.02$ & 0.71 & .726 & .685 & .945 \\
\hline SR10 & $\begin{array}{l}\text { find standpoints / behaviour pattern which allow } \\
\text { pleasant problem solving }\end{array}$ & $4.03 \pm 1.01$ & 0.67 & .718 & .746 & .944 \\
\hline SR7 & attain most important objectives & $4.15 \pm 0.98$ & 0.69 & .695 & .752 & .944 \\
\hline SR9 & $\begin{array}{l}\text { disappointment: no reason for resignation, but cause } \\
\text { to change behaviour }\end{array}$ & $4.07 \pm 1.02$ & 0.68 & .674 & .672 & .946 \\
\hline SR13 & $\begin{array}{l}\text { because of behaviour desired proximity and required } \\
\text { distance to important others }\end{array}$ & $4.17 \pm 0.99$ & 0.70 & .627 & .669 & .946 \\
\hline SR4 & $\begin{array}{l}\text { expand various activities until states change to total } \\
\text { satisfaction }\end{array}$ & $3.66 \pm 1.11$ & 0.61 & .614 & .577 & .948 \\
\hline & \multicolumn{6}{|c|}{ 2. Achieve Satisfaction and Well-Being ( $\alpha=0.848 ; 31.5 \%$ of variance) } \\
\hline SR15 & well-being by daily activities & $4.02 \pm 1.06$ & 0.67 & .822 & .713 & .945 \\
\hline SR14 & $\begin{array}{l}\text { inner satisfaction over and over again by daily } \\
\text { activities }\end{array}$ & $4.13 \pm 1.05$ & 0.69 & .737 & .757 & .944 \\
\hline SR2 & actualize wishes and satisfy needs & $3.85 \pm 1.07$ & 0.64 & .735 & .700 & .945 \\
\hline SR5 & arrange different areas of life optimal & $3.93 \pm 1.03$ & 0.66 & .726 & .744 & .944 \\
\hline SR3 & situations / states which restore well-being & $3.87 \pm 1.04$ & 0.65 & .720 & .755 & .944 \\
\hline SR1 & situations / states which motivate & $3.97 \pm 1.07$ & 0.66 & .668 & .671 & .946 \\
\hline SR8 & $\begin{array}{l}\text { situations / states which satisfy wishes and needs } \\
\text { optimal }\end{array}$ & $3.95 \pm 1.00$ & 0.67 & .651 & .794 & .943 \\
\hline SR16 & $\begin{array}{l}\text { behaviour gives rise to situations which cause } \\
\text { experiences full of relish }\end{array}$ & $3.76 \pm 1.03$ & 0.63 & .628 & .658 & .946 \\
\hline
\end{tabular}

Varimax Rotation with Kaiser Normalization (rotation converged in 3 Iterations);

Kaiser-Mayer-Olkin value $=0.95$; Barlett's test for non-sphericity $\mathrm{p}<0,001$

tients with coronary heart disease (which are predominantly male), and the lowest in patients with Hashimoto's thyreoiditis and with multi-conditions.

If one analyses the inter-subject effects of the variables gender, age and disease, it became evident that for the scale Ability to Change Behaviour gender was of significant relevance $(F=5.28 ; p=0.022)$, while for the scale Achieve Satisfaction and Well-Being only the disease group was of importance $(\mathrm{F}=2.64 ; \mathrm{p}=$ $0.008)$.

\section{EXTERNAL VALIDITY}

The Ability to Achieve Satisfaction and Well-Being was strongly $(\mathrm{r}>0.5)$ and negatively correlated with anxiety and depression, and positively with HRQL, particularly with Initiative Power/Interest. There were several moderate correlations between the SRQ scales and HRQL dimensions and aR (Table 3). In contrast, Physical complaints correlated just weakly with SR. When controlled for age, the magnitude of the respec- tive correlations did not change considerably (data not shown).

\section{Discussion}

The 16-item SRQ had a very good internal consistence and differentiates Ability to Change Behaviour in order to reach goals, and Achieve Satisfaction and WellBeing. The later factor has an obvious hedonistic / eudemonistic connotation, while the first factor can be viewed in the context of problem solving and coping which approaches to the concept of an internal 'locus of control' $[18,19]$ and also Antonovsky's coherence concept (with the three principles of comprehensibility, meaningfulness, manageability) [20].

With respect to external validity, the SRQ sub-scales correlated best with Initiative Power / Interest (and also with Social Interaction and Mental balance), and negatively with anxiety and depression, which underlines the aspect of a creative problem solving capacity. 
Table 2. Mean values of SRQ scores differentiated with respect to gender, and disease status of tested individuals.

\begin{tabular}{lcc}
\hline & $\begin{array}{c}\text { Ability to Change Behaviour in } \\
\text { order to reach goals }\end{array}$ & $\begin{array}{c}\text { Achieve Satisfaction and } \\
\text { Well-Being }\end{array}$ \\
\hline all individuals (n=444) & $67.3 \pm 13.2$ & $65.9 \pm 14.5$ \\
\hline Gender & $66.1 \pm 13.3$ & $65.2 \pm 14.5$ \\
Female (73\%) & $70.5 \pm 12.4$ & $67.5 \pm 14.3$ \\
Male (27\%) & 10.591 & 2.272 \\
\hline \multicolumn{1}{c}{ F-value } & $\mathbf{0 . 0 0 1}$ & n.s. \\
\hline p-value & $71.6 \pm 10.5$ & $71.0 \pm 11.0$ \\
Individuals & $64.1 \pm 13.5$ & $63.7 \pm 14.6$ \\
Healthy controls & $67.0 \pm 14.2$ & $65.3 \pm 13.6$ \\
Breast cancer & $65.2 \pm 16.9$ & $63.4 \pm 20.7$ \\
Colorectal cancer & $66.4 \pm 13.6$ & $63.8 \pm 13.8$ \\
Diabetes mellitus & $70.2 \pm 12.7$ & $67.8 \pm 13.7$ \\
Rheumatic diseases & $64.6 \pm 8.3$ & $62.3 \pm 10.4$ \\
Coronary heart diseases & $64.2 \pm 12.0$ & $59.3 \pm 13.7$ \\
Hashimoto's thyreoiditis & 3.131 & 3.417 \\
multi conditions & $\mathbf{0 . 0 0 2}$ & $\mathbf{0 . 0 0 1}$ \\
\hline \multicolumn{1}{c}{ F-value } & &
\end{tabular}

Table 3. Correlation analyses between SRQ subscales and other psychological variables.

\section{SRQ Factors}

\begin{tabular}{lcc} 
& $\begin{array}{c}\text { Ability to Change Behaviour } \\
\text { in order to reach goals }\end{array}$ & $\begin{array}{c}\text { Achieve Satisfaction } \\
\text { and Well-Being }\end{array}$ \\
\hline SRQ - Ability to Change Behaviour & 1.00 & .77 \\
SRQ - Achieve Satisfaction and Well-Being & .77 & 1.00 \\
\hline HADS - Anxiety & -.41 & $\mathbf{- . 5 2}$ \\
HADS - Depression & -.45 & $\mathbf{- . 6 5}$ \\
\hline HLQ Sum Score $\quad$ Initiative Power / Interest & .40 & $\mathbf{. 5 5}$ \\
$\quad$ Social interaction & .46 & $\mathbf{. 5 8}$ \\
Mental balance & .37 & .48 \\
Motility & .33 & .48 \\
Digestive well-being & .26 & .37 \\
Physical complaints & .20 & .33 \\
& .17 & .28 \\
\hline Autonomic regulation & .27 & .34 \\
\hline
\end{tabular}

* all correlations are significant at the 0.01 level (Spearman's rho; 2-tailed)

The HLQ scale Initiative Power and Interests heeds topics such as decisiveness, spontaneous reactions, planful actions, adaptation to persons and situations, enhanced personality feeling of security, etc. and thus is in line with the primary concept of the SR. With respect to construct validity, the SRQ deals with competence and autonomy in social concerns, with an active initiative problem solving capacity. SR can be regarded as an active cognitive process in terms of an adapta- tion to stressful situations (i.e., illness) or displeasing conditions. In contrast to the coping concept of Folkman and Lazarus [21], SR does not focus on the regulation of emotions to avoid stressful situations, but to actively change the unpleasant conditions and to restore well-being. Thus, the SRQ heeds both intrinsic abilities to change behaviour and attitudes, and extrinsic abilities to modify external life concerns. Particularly problem-solving coping strategies were inversely re- 
lated to psychological distress [22]; and this may be related with higher survival times as observed in cancer patients treated with complementary medicine and higher SR scores [23].

Taken together, the SRQ was found to be a valid and reliable tool which deals with competence and autonomy and can be regarded as a problem solving capacity in terms of an active adaptation to stressful situations to restore well-being. We can not draw any conclusion whether higher SR may impact the courses of disease and thus quality of life - or whether HRQL and autonomic regulation are the 'regulators' of SR. Further studies have to clarify the possible clinical implications of low SR as contrasted with high SR, as indicated by the finding of higher survival times in cancer patients with higher SR scores [23]. Nevertheless, the tool is an interesting option to be used particularly in complementary medicine research with a focus on behavioural modification.

Acknowledgement: We thank Dagmar Brauer for data-base documentation, Hans Broder von Laue and Roland Zerm for participation in recruitment. This study has been supported by the Humanus-Institut e.V., Kandern (Germany), and MK has been supported by Software AG foundation, Darmstadt (Germany).

\section{REFERENCES}

1. Rose M, Kohler K, Kohler F, Sawitzky B, Fliege H, Klapp BF: Determinants of the quality of life of patients with congenital heart disease. Qual Life Res 2005, 14: 3543.

2. Poppius E, Virkkunen H, Hakama M, Tenkanen L: The sense of coherence and incidence of cancer--role of follow-up time and age at baseline. J Psychosom Res 2006, 61: 205-211.

3. Gotay CC, Isaacs P, Pagano I: Quality of life in patients who survive a dire prognosis compared to control cancer survivors. Psychooncology 2004, 13: 882-892.

4. Grossarth-Maticek R, Kiene H, Baumgartner SM, Ziegler R: Use of Iscador, an extract of European mistletoe (Viscum album), in cancer treatment: prospective nonrandomized and randomized matched-pair studies nested within a cohort study. Altern Ther Health Med 2001, 7 : 57-78.

5. Grossarth-Maticek R, Ziegler R: Randomised and nonrandomised prospective controlled cohort studies in matched-pair design for the long-term therapy of breast cancer patients with a mistletoe preparation (Iscador): a re-analysis. Eur J Med Res 2006, 11: 485-495.

6. Grossarth-Maticek R, Ziegler R: Prospective controlled cohort studies on long-term therapy of breast cancer patients with a mistletoe preparation (Iscador). Forsch Komplement Med 2006, 13: 285-292.

7. Grossarth-Maticek R, Ziegler R: Prospective controlled cohort studies on long-term therapy of ovarian cancer patients with mistletoe (Viscum album L.) extracts iscador. Arzneimittelforschung 2007, 57: 665-678.

8. Grossarth-Maticek R, Ziegler R: Prospective controlled cohort studies on long-term therapy of cervical cancer patients with a mistletoe preparation (Iscador). Forsch Komplement Med 2007, 14: 140-147.
9. Grossarth-Maticek R, Ziegler R: Randomised and nonrandomised prospective controlled cohort studies in matched-pair design for the long-term therapy of corpus uteri cancer patients with a mistletoe preparation (Iscador). Eur J Med Res 2008, 13: 107-120.

10. Grossarth-Maticek R: Autonomietraining. Gesundheit und Problemlösung durch Anregung der Selbstregulation. Berlin, New York: de Gruyter; 2008.

11. Ostermann T, Büssing A, Beer AM, Matthiessen PF: The Herdecke Questionnaire on Quality of Life (HLQ): validation of factorial structure and development of a short form within a naturopathy treated in-patient collective. Health Qual Life Outcomes 2005, 3, 40.

12. Zigmond AS, Snaith RP: The hospital anxiety and depression scale. Acta Psychiatr Scand 1983, 67: 361-370.

13. Herrmann C: International experiences with the Hospital Anxiety and Depression Scale--a review of validation data and clinical results. J Psychosom Res 1997, 42: 17-41.

14. Kröz M, Feder G, von LH, Zerm R, Reif M, Girke M et al.: Validation of a questionnaire measuring the regulation of autonomic function. BMC Complement Altern Med 2008, 8: 26

15. Kröz M, von Laue HB, Zerm R, Girke M: [Development of a questionnaire for endogenous regulation--a contribution for salutogenesis research]. Forsch Komplementarmed Klass Naturheilkd 2003, 10: 70-77.

16. Cronbach L: Coefficient alpha and the internal structure of the tests. Psychomerika 1951, 16: 297-334.

17. Büssing A, Ostermann T, Matthiessen PF: Role of religion and spirituality in medical patients: confirmatory results with the SpREUK questionnaire. Health Qual Life Outcomes 2005, 3: 10.

18. Levenson H: Distinctions Within the Concept of Internal-External Control: Development of a New Scale. Proceedings of the 80th Annual Convention of the American Psychological Association 1972, 7: 261-262.

19. Rotter J: Generalized expectations for internal versus external control reinforcement. Psychological Monographs: General and Applied Psychology 1966, 80: 1-27.

20. Antonovsky A: Unraveling the mystery of health. How people manage stress and stay well. San Francisco, London: Jossey-Bass; 1987.

21. Folkman S, Lazarus RS: The relationship between coping and emotion: implications for theory and research. Soc Sci Med 1988, 26: 309-317.

22. Andenaes R, Kalfoss MH, Wahl AK: Coping and psychological distress in hospitalized patients with chronic obstructive pulmonary disease. Heart Lung 2006, 35: 46-57.

23. Grossarth-Maticek R: Systemische Epidemiologie und präventive Verhaltensmedizin chronischer Erkrankungen. Strategien zur Aufrechterhaltungen der Gesundheit. Berlin, New York: de Gruyter; 1999.

Received: February 2, 2009 / Accepted: March 6, 2009

Address for correspondence:

Prof. Dr. med. Arndt Büssing

University Witten/Herdecke

Chair of Medical Theory and Complementary Medicine

Gerhard-Kienle-Weg 4

58313 Herdecke

Germany

Phone: +49-2330-623246

Fax: +49-2330-623358

E-mail: arndt.buessing@uni-wh.de 